\title{
Radionuclide Generator
}

National Cancer Institute

\section{Source}

National Cancer Institute. Radionuclide Generator. NCI Thesaurus. Code C94966.

A device that produces a useful radionuclide from a parent substance contained within.

As the parent decays a daughter, the useful radionuclide, is created and amounts may be obtained from the generator as needed. 